\title{
A comparison of three multidimensional indices of COPD severity as predictors of future exacerbations
}

This article was published in the following Dove Press journal:

International Journal of COPD

30 May 2013

Number of times this article has been viewed

\section{Takashi Motegi ${ }^{1,2}$ \\ Rupert C Jones ${ }^{3}$ \\ Takeo Ishii ${ }^{1,2}$ \\ Kumiko Hattori ${ }^{1,2}$ \\ Yuji Kusunoki ${ }^{1,2}$ \\ Ryuko Furutate ${ }^{2}$ \\ Kouich Yamada ${ }^{1,2}$ \\ Akihiko Gemma' \\ Kozui Kida ${ }^{1,2}$}

'Divisions of Pulmonary Medicine, Infectious Disease, and Oncology, Department of Internal Medicine, ${ }^{2}$ Respiratory Care Clinic, Nippon Medical School, Tokyo, Japan;

${ }^{3}$ Respiratory Research Unit, Peninsula Medical School, Plymouth, UK
Correspondence: Takashi Motegi Respiratory Care Clinic, Nippon Medical School, 4-7-15-8F, Kudan-minami, Chiyoda-ku, Tokyo, I02-0074, Japan

Tel +8I 352762325

Fax +8I 352762326

Email mo-dr@nms.ac.jp
Background: Prediction of future exacerbations of chronic obstructive pulmonary disease (COPD) is a major concern for long-term management of this disease.

Aim: To determine which of three multidimensional assessment systems (the body mass index, obstruction, dyspnea, and exercise capacity [BODE] index; dyspnea, obstruction, smoking, exacerbations [DOSE] index; or age, dyspnea, obstruction [ADO] index) is superior for predicting exacerbations.

Methods: This was a 2-year prospective cohort study of COPD patients. Pulmonary function tests, the 6-minute walk distance (6MWD), Modified Medical Respiratory Council (MMRC) dyspnea scores, chest computed-tomography measurements, and body composition were analyzed, and predictions of exacerbation by the three assessment systems were compared.

Results: Among 183 patients who completed the study, the mean annual exacerbation rate was 0.57 events per patient year, which correlated significantly with lower predicted forced expiratory volume in 1 second $\left(\mathrm{FEV}_{1}\right)(P<0.001)$, lower transfer coefficient of the lung for carbon monoxide (\%DLco/VA) $(P=0.021)$, lesser 6MWD $(P=0.016)$, higher MMRC dyspnea score $(P=0.001)$, higher DOSE index $(P<0.001)$, higher BODE index $(P=0.001)$, higher ADO index $(P=0.001)$, and greater extent of emphysema $(P=0.002)$. For prediction of exacerbation, the areas under the curves were larger for the DOSE index than for the BODE and ADO indices $(P<0.001)$. Adjusted multiple logistic regression identified the DOSE index as a significant predictor of risk of COPD exacerbation.

Conclusion: In this study, the DOSE index was a better predictor of exacerbations of COPD when compared with the BODE and ADO indices.

Keywords: frequency of exacerbation, multidimensional assessment systems, DOSE index, BODE index

\section{Introduction}

The current Global initiative for chronic Obstructive Lung Disease (GOLD) ${ }^{1}$ strategy states that exacerbations of chronic obstructive pulmonary disease (COPD) are important events in the course of the disease because they: (1) negatively affect a patient's quality of life; (2) have effects on symptoms and lung function from which the patient may require several weeks to recover; (3) accelerate the rate of decline of lung function; (4) are associated with significant mortality, particularly in those requiring hospitalization; and (5) have high socioeconomic costs. However, as described by GOLD, early detection of exacerbation is occasionally difficult in cases where mild symptoms persist and then rapidly worsen prior to the commencement of sufficient courses of medication. ${ }^{1}$ Thus, a proper and simple prediction tool is important, particularly in routine clinical care. 
Previous studies have suggested several predictors of exacerbations of COPD, including chronic bronchitis, a reduced forced expiratory volume over 1 second $\left(\mathrm{FEV}_{1}\right)$, advanced age, long-term oxygen therapy (LTOT), systemic steroid therapy, exacerbation(s) within the previous year, and hospitalization. ${ }^{2-4}$ Moreover, the GOLD guidelines ${ }^{1}$ recently recommended classifying patients with COPD by the severity of their symptoms and the risk of future exacerbations.

The body mass index, obstruction, dyspnea, exercise capacity (BODE) index was the first multidimensional assessment system for COPD. This multicomponent index was shown to be superior to $\mathrm{FEV}_{1}$ alone for prediction of outcomes. ${ }^{5}$ Thereafter, two major multidimensional assessment systems similar to the BODE index have been published: ${ }^{67}$ the age, dyspnea, and airflow obstruction (ADO) index and the dyspnea, airflow obstruction, smoking status, and the frequency of exacerbations in the last year (DOSE) index, both of which are suitable for routine clinical care including primary care.

In the present study, our primary aim was to identify which of the three multidimensional assessment systems, the BODE, DOSE, or ADO indices, best predicts the risk of future exacerbations.

\section{Methods}

\section{Participants}

A total of 232 outpatients with COPD who were initially seen in the outpatient Respiratory Care Clinic (RCC), a secondary care specialty COPD clinic of Nippon Medical School, Tokyo, Japan, from April 2007 to October 2007 were enrolled. All participants were aged $\geq 40$ years and were either current or former smokers. Detailed inclusion and exclusion criteria are provided in the Supplementary materials. COPD was diagnosed according to the GOLD 2006 guidelines. ${ }^{8}$

The study was approved by the ethics committee of the institution, and patients were enrolled only after providing appropriate written informed consent to participate.

\section{Study design}

All patients were asked to visit our clinic once per month from November 2007 to October 2009. At each visit during the study period, a research nurse carefully inquired whether the patient had shown any symptoms of an exacerbation since their previous visit; these signs were based on both a diary and self-assessment (Figure S1). The primary symptoms and their date(s) of onset and duration, as well as any medications that were changed or added during the exacerbation(s), were recorded. The occurrence of exacerbations was recorded once per month; however, these occurrences were recorded at least bimonthly during the study period if the patient could not visit the clinic. All patients underwent repeated pulmonary function tests, a 6-minute walk distance (6MWD) test, and nutritional assessments every six months during the study period. To predict exacerbations of COPD, the data collected during the first year were used to estimate the occurrence of exacerbation during the second year. We excluded from the final evaluation in the following cases: death or transfer to another clinic during the first year or lack of data. Patients who died during the second year were included.

\section{Measurements}

Pulmonary functional parameters were measured according to the American Thoracic Society (ATS) guidelines. ${ }^{9}$ Reference post-bronchodilator values were based on the Japanese Respiratory Society standards. ${ }^{10}$ The severity of COPD was classified according to the $\mathrm{FEV}_{1} \%$ and was predicted as Stage I-IV, as described in the GOLD guidelines. ${ }^{8}$ The degree of dyspnea was assessed at the same time during each of the pulmonary function tests by using the Modified Medical Research Council (MMRC) dyspnea scale. ${ }^{11}$ The research nurse performed the 6MWD test according to the ATS standard. ${ }^{12}$ Body mass index (BMI) was calculated by dividing the weight in kilograms by the square of the height in meters and fat-free mass (FFM) was measured by bioelectrical impedance analysis (InBody 3.2; Biospace Japan, Inc, Tokyo, Japan). The FFM index (FFMI) was calculated as the ratio of the FFM to the height in meters squared. The extent of emphysema, measured by both the percentage of low-attenuation area (LAA\%) and airway wall thickness (percentage of airway wall area [WA\%]), was determined with high-resolution computed tomography (CT) images. The details of the visual assessment are provided in the Supplementary materials. Comorbidities were determined from the medical records and were quantified by using the Charlson comorbidity index. ${ }^{13}$

\section{Assessment of exacerbations}

Each exacerbation was carefully assessed according to a symptom-based definition, ie, onset or worsening of more than two symptoms (dyspnea, sputum purulence or volume, cough, or wheeze) for more than 2 consecutive days. Detailed information is provided in the Supplementary materials. Each exacerbation recorded in a patient's daily diary over the entire 2-year study period was thoroughly evaluated with accordance by three authors (TM, TI, and KK) and the research nurse, and 
the events were confirmed by reviewing the patient's medical records and blood chemistry or chest radiographs, if these were taken at every clinic visit. The rate of annual exacerbation was calculated for each year of the study period.

\section{Multidimensional assessments}

We used three multidimensional assessments, the original versions of the BODE, ADO, and DOSE indices, ${ }^{5-7}$ and we calculated each score by using the data that had been collected at the end of October 2008 or within one month of that date. Smoking status was also reassessed at this time. The rates of previous exacerbation for the DOSE index were calculated based on the exacerbation frequencies during the first year of the study period (November 2007 to October 2008).

\section{Statistical analysis}

Cases with and without episodes of exacerbation were compared by using the unpaired $t$-test for continuous variables and the Mann-Whitney test for ordinal variables. The $\chi^{2}$ test of contingency tables was applied to compare proportions of discrete variables. We divided the participants into two groups according to the occurrence of exacerbations during the second year of the study period (November 2008 to October 2009). The results of the GOLD stages, BODE index, ADO index, and DOSE index were compared between these groups using receiver operating curves (ROC). The area under the curve (AUC) of the ROC was calculated, and it ranged from 0 to 1 , with 1 indicating perfect discrimination and 0.5 indicating a chance of discrimination. AUC $>0.7$ has been found to indicate good discrimination. ${ }^{14}$ Adjusted multiple logistic regression models including independent variables associated with exacerbation during univariate analysis were also constructed, and four models were tested. Model I did not include any of the multidimensional assessment systems, model II included the BODE index, model III the ADO index, and model IV the DOSE index. Parameters already included in the BODE, ADO, or DOSE indices were excluded from models II, III, and IV, respectively.

The correlation of the frequency of exacerbations within the last year with BMI, FFMI, 6MWD, LAA\%, diffusing capacity of the lung for carbon monoxide and alveolar volume ratio (\%DLco/VA), $\mathrm{PaO}_{2}$, and $\mathrm{PaCO}_{2}$ were examined using Spearman's rank correlation test. These parameters were further tested for correlation with the BODE, ADO, and DOSE indices.

All statistical analyses were performed using JMP for Windows, version 9.0 (SAS Institute Japan Ltd, Tokyo, Japan). A $P$-value of $<0.05$ was considered statistically significant.

\section{Results}

A flow chart depicting the patient selection process is shown in Figure 1. Of the 232 COPD patients who were initially enrolled, 26 were excluded because of withdrawal

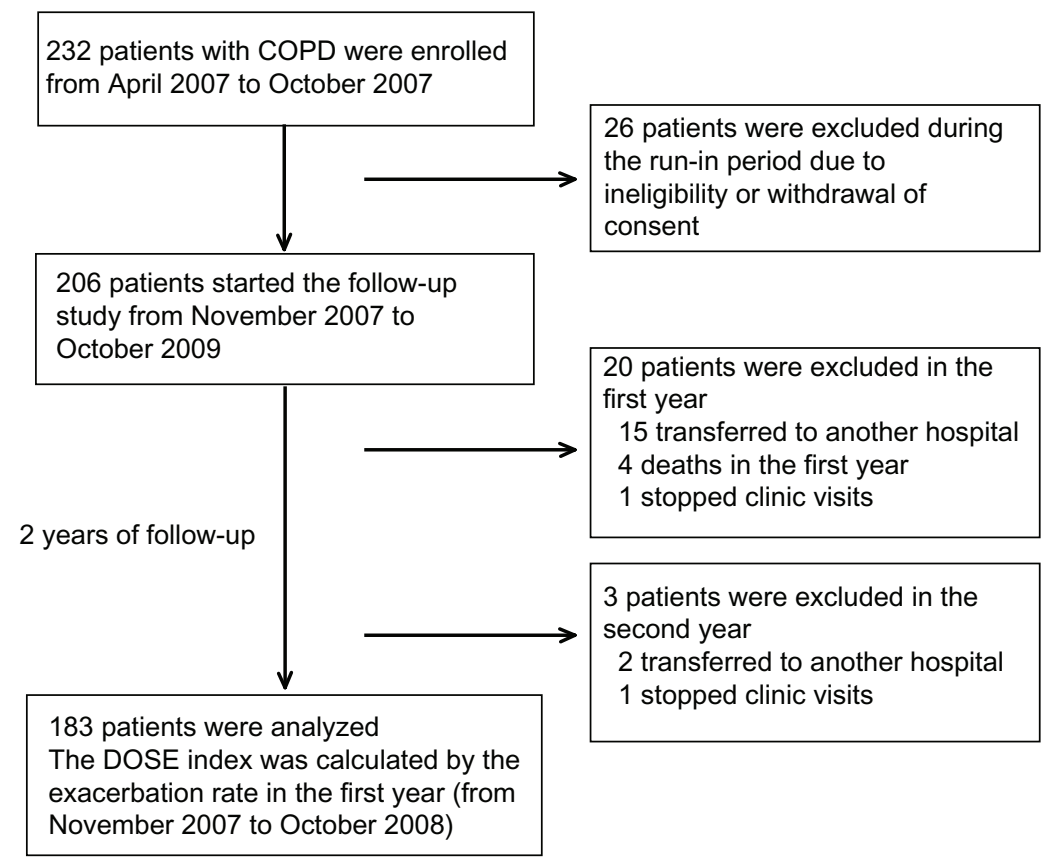

Figure I Flow chart for patient selection.

Abbreviations: COPD, chronic obstructive pulmonary disease; DOSE, dyspnea, obstruction, smoking, exacerbations. 
of consent or ineligibility for inclusion during the run-in period. Therefore, 206 patients were finally included, and 183 completed the study.

The characteristics of the patients who were classified as those who did or who did not experience exacerbations during the second year of the study are shown in Table 1. The overall mean age was 71 years, males predominated, and the percentages of patients in each stage of the GOLD classification were $13.7 \%, 42.6 \%, 33.9 \%$, and $9.8 \%$ for stages I, II, III, and IV, respectively.

\section{Frequency of exacerbations and correlated factors}

The numbers of exacerbations in the first and second years were 105 and 88, respectively. The mean rates of exacerbation for the entire group in the first and second years of the study were 0.57 and 0.48 events per patient-year, respectively. Sixty-four patients (35\%) experienced at least one exacerbation during the second year: 47 of these $(73 \%)$ experienced one episode and 17 reported two or more exacerbations. Sixteen patients required hospitalization during the second year.

Patients who experienced exacerbations during the second year had significantly lower $\mathrm{FEV}_{1} \%$ predicted values,
$\% \mathrm{DLco} / \mathrm{VA}$, and 6MWD results, significantly higher LAA $\%$ values, MMRC scores, and rates of exacerbation during the previous year, and more severe GOLD stages than those who did not experience exacerbations. All of the multidimensional assessment scores were significantly worse in patients who experienced exacerbations than in those who did not.

\section{Comparisons of multidimensional assessments}

The ROC curves of the GOLD stage and the BODE, ADO, and DOSE indices are shown in Figure 2. The AUC values for prediction of exacerbations for the DOSE index, GOLD stage, BODE index, and ADO index were 0.75, 0.66, 0.65, and 0.64 , respectively. Although all of these were significant predictors, the value for the DOSE index was much greater than the values for the other assessments $(P<0.001)$. However, a statistically significant difference was not observed between the AUC for the previous exacerbation rate, which was 0.71 , and the data of the DOSE index $(P=0.40)$. The results of univariate analysis of predictors of exacerbation are shown in Table 2 . The predictor of exacerbation with the greatest odds ratio (OR) by simple logistic analysis was LTOT (OR 4.17, 95\% confidence interval

Table I Baseline characteristics of patients with COPD according to the occurrence of exacerbation during a I-year period

\begin{tabular}{|c|c|c|c|c|}
\hline Characteristic & Total & With exacerbation & Without exacerbation & $P$-value \\
\hline Gender, M/F & $170 / 13$ & $62 / 2$ & $108 / 11$ & 0.105 \\
\hline Age $(y)$ & $71.4 \pm 8.7$ & $72.5 \pm 9.1$ & $70.8 \pm 8.5$ & 0.229 \\
\hline $\mathrm{FEV}_{1}(\mathrm{~L})$ & $1.50 \pm 0.64$ & $1.27 \pm 0.66$ & $\mathrm{I} .63 \pm 0.6 \mathrm{I}$ & $<0.001$ \\
\hline FEV $\%$ predicted (\%) & $55.7 \pm 20.7$ & $47.8 \pm 18.1$ & $59.9 \pm 20.9$ & $<0.001$ \\
\hline \%DLco/VA (\%) & $59.2 \pm 22.8$ & $53.9 \pm 20.3$ & $62.0 \pm 23.5$ & 0.002 \\
\hline LTOT use (\%) & 40.4 & 62.5 & 37.5 & $<0.001$ \\
\hline $\mathrm{PaO}_{2}$ (torr) & $80.1 \pm 12.1$ & $82.6 \pm 14.1$ & $79.9 \pm 10.9$ & 0.166 \\
\hline $\mathrm{PaCO}_{2}$ (torr) & $41.9 \pm 5.2$ & $42.8 \pm 5.1$ & $41.4 \pm 5.3$ & 0.113 \\
\hline Current smoking (\%) & 4.4 & 4.7 & 4.2 & 0.575 \\
\hline Smoking pack-years & $75.6 \pm 45.3$ & $82.1 \pm 47.1$ & $72.1 \pm 44.1$ & 0.159 \\
\hline GOLD stage I/II/III/IV (n) & $25 / 78 / 62 / 18$ & $6 / 17 / 31 / 10$ & $|9 / 6| / 3 \mid / 8$ & 0.001 \\
\hline BMI $\left(\mathrm{kg} / \mathrm{m}^{2}\right)$ & $22.2 \pm 3.1$ & $21.9 \pm 2.5$ & $22.4 \pm 3.4$ & 0.235 \\
\hline FFMI $\left(\mathrm{kg} / \mathrm{m}^{2}\right)$ & $17.0 \pm 1.7$ & $16.7 \pm 1.4$ & $17.1 \pm 1.8$ & 0.116 \\
\hline 6MWD (m) & $464.1 \pm 111.9$ & $436.7 \pm 107.1$ & $478.6 \pm 112.1$ & 0.016 \\
\hline MMRC dyspnea scale & $1.3 \pm 1.0$ & $1.6 \pm 1.0$ & $\mathrm{I} . \mathrm{I} \pm 0.9$ & 0.001 \\
\hline LAA\% & $34.1 \pm 14.8$ & $38.7 \pm 14.4$ & $31.6 \pm 14.5$ & 0.002 \\
\hline WA\% & $53.9 \pm 12.5$ & $55.4 \pm 11.5$ & $53.1 \pm 13.0$ & 0.237 \\
\hline Charlson index & $2.6 \pm 1.0$ & $2.6 \pm 0.9$ & $2.6 \pm 1.0$ & 0.84 \\
\hline BODE index & $2.4 \pm 2.2$ & $3.1 \pm 2.2$ & $2.1 \pm 2.1$ & 0.001 \\
\hline ADO index & $4.0 \pm 1.7$ & $4.5 \pm 1.7$ & $3.7 \pm 1.6$ & 0.001 \\
\hline DOSE index & $1.3 \pm 1.4$ & $2.1 \pm 1.5$ & $0.9 \pm 1.2$ & $<0.001$ \\
\hline Previous exacerbation rate & $0.57 \pm 0.98$ & $1.13 \pm 1.28$ & $0.28 \pm 0.58$ & $<0.001$ \\
\hline
\end{tabular}

Note: Data are expressed as means \pm SD except where otherwise noted.

Abbreviations: 6MWD, 6-minute walking distance; ADO, age/dyspnea/airflow obstruction; BMI, body mass index; BODE, body mass index/airflow obstruction/dyspnea/ exercise capacity; COPD, chronic obstructive pulmonary disease; DLco/VA, diffusing capacity of the lung for carbon monoxide and alveolar volume ratio; DOSE, dyspnea/ airflow obstruction/smoking status/exacerbation frequency; FEV , forced expiratory volume in I second; FFMI, fat-free mass index; GOLD, Global initiative for chronic Obstructive Lung Disease; LAA\%, percentage of low-attenuation area; LTOT, long-term oxygen therapy; MMRC, Modified Medical Research Council dyspnea scale; Previous exacerbation, exacerbation of COPD within the previous year; SD, standard deviation; WA\%, percentage of airway wall area. 


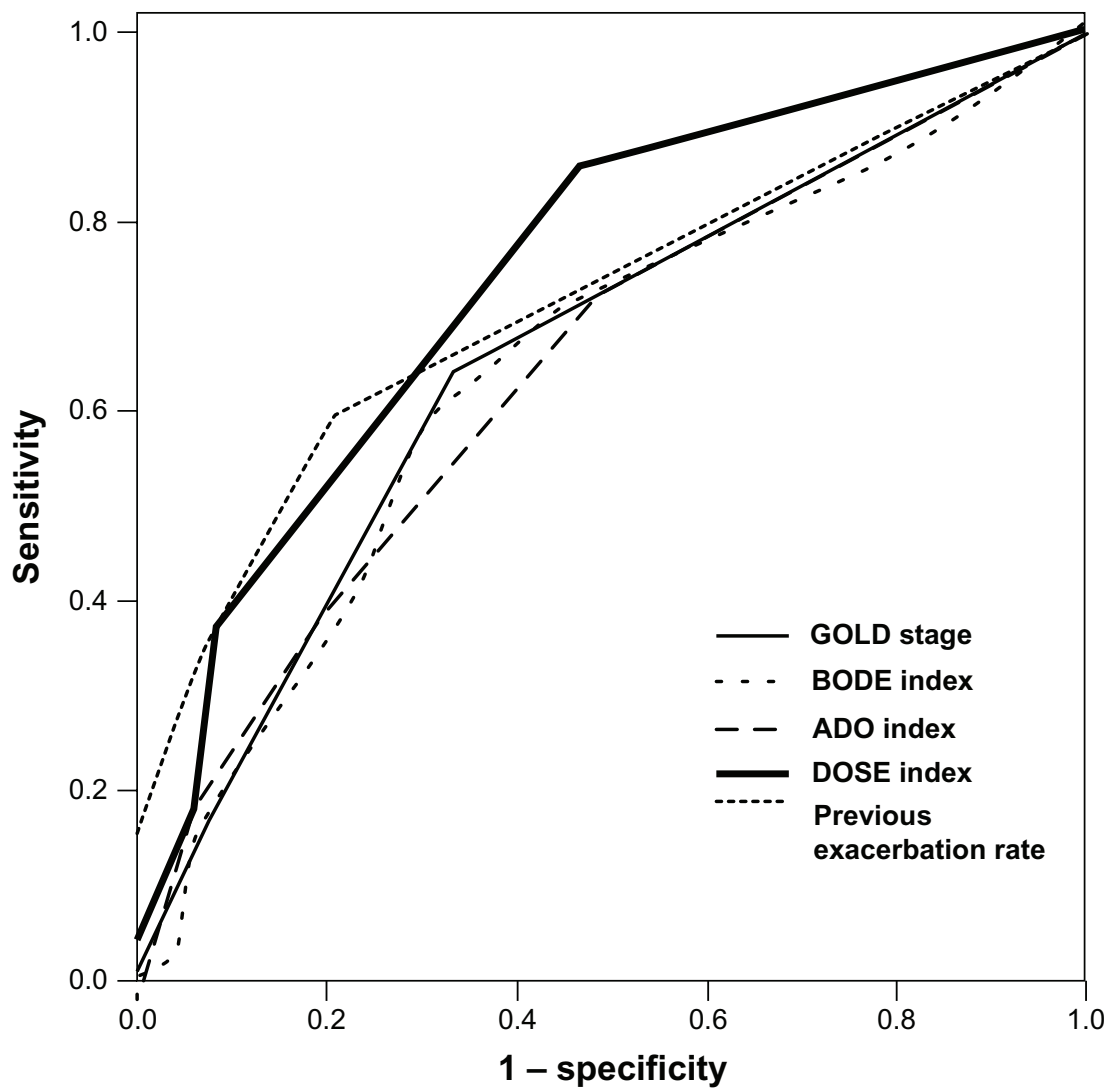

\begin{tabular}{|c|c|c|}
\hline & AUC (95\% Cl) & $P$-value \\
\hline GOLD stage & $0.66(0.57-0.74)$ & $<0.001$ \\
\hline BODE index & $0.65(0.56-0.73)$ & 0.001 \\
\hline ADO index & $0.64(0.56-0.73)$ & 0.001 \\
\hline DOSE index & $0.75(0.67-0.82)$ & $<0.001$ \\
\hline Previous exacerbation rate & $0.71(0.63-0.80)$ & $<0.001$ \\
\hline
\end{tabular}

Figure 2 Receiver-operator curves for the multidimensional grading systems, GOLD stage, and previous exacerbation rate as predictors of the occurrence of exacerbation during the I-year follow-up.

Notes: The AUC and the $95 \% \mathrm{Cl}$ are shown for each index. The AUC for the DOSE index is significantly larger than for the other multidimensional assessments or GOLD stage $(P<0.00 \mathrm{I})$, but shows no difference versus previous exacerbation rate $(P=0.40)$.

Abbreviations: AUC, area under the curve; ADO, age/dyspnea/airflow; BODE, body mass index/airflow obstruction/dyspnea/exercise capacity; Cl, confidence interval; DOSE, dyspnea, obstruction, smoking, exacerbations GOLD, Global initiative for chronic Obstructive Lung Disease.

$[95 \% \mathrm{CI}]=2.19-7.93, P<0.001)$. The OR for frequency of exacerbations in the previous year was similarly high at $2.79(95 \% \mathrm{CI}=1.85-4.21, P<0.001)$, while the OR $(95 \%$ $\mathrm{CI})$ results for the $\mathrm{BODE}, \mathrm{ADO}$, and DOSE indices were 1.26 (1.09-1.45), 1.36 (1.11-1.64), and 1.90 (1.48-2.43), respectively. No significant predictive values were found for BMI, FFM, or results of arterial blood gas analysis.

\section{Prediction of exacerbation}

The results for prediction of exacerbations by adjusted multiple regression analysis are shown in Table 3. In model I, two variables appeared to be significant: MMRC (OR 1.81,
$P=0.001)$ and frequency of exacerbations in the previous year (OR 2.98, $P<0.001$ ). In model II, which included the BODE index, LTOT (OR 2.92, $P=0.003)$ and the frequency of exacerbations in the previous year (OR 2.57, $P<0.001$ ) were significantly correlated with the occurrence of exacerbations, although the BODE index itself did not reach statistical significance. In model III, which included the ADO index, the ADO index (OR 1.40, $P=0.002$ ) and the frequency of exacerbations in the previous year appeared to be significant predictors (OR 2.92, $P<0.001$ ). In model IV, which included the DOSE index, the DOSE index (OR 2.19, $P<0.001)$ and LTOT use (OR 2.37, $P=0.024)$ reached significance. 
Table 2 Univariate analysis of predictors of COPD exacerbation

\begin{tabular}{|c|c|c|c|}
\hline Variable & Odds ratio & $95 \% \mathrm{Cl}$ & $P$-value \\
\hline Age & 1.03 & $0.99-1.06$ & 0.160 \\
\hline Previous exacerbation & 2.79 & $|.85-4.2|$ & $<0.001$ \\
\hline GOLD stage & 2.00 & $1.35-2.96$ & 0.001 \\
\hline BODE index & 1.26 & $1.09-1.45$ & 0.002 \\
\hline ADO index & 1.36 & $1.11-1.64$ & 0.002 \\
\hline DOSE index & 1.90 & $1.48-2.43$ & $<0.001$ \\
\hline MMRC & 1.72 & $1.24-2.40$ & 0.001 \\
\hline 6MWD & 0.99 & $0.94-0.99$ & 0.018 \\
\hline BMI & 0.94 & $0.85-1.04$ & 0.235 \\
\hline FFMI & 0.86 & $0.7 I-I .04$ & 0.118 \\
\hline LAA\% & 1.03 & $1.01-1.06$ & 0.003 \\
\hline $\mathrm{FEV}, \%$ predicted & 0.97 & $0.95-0.99$ & $<0.001$ \\
\hline \%DLco/VA & 0.98 & $0.97-0.99$ & 0.023 \\
\hline LTOT use & 4.17 & $2.19-7.93$ & $<0.001$ \\
\hline $\mathrm{PaO}_{2}$ & 1.02 & $0.99-1.05$ & 0.170 \\
\hline $\mathrm{PaCO}_{2}$ & 1.05 & $0.99-1.12$ & 0.119 \\
\hline Charlson index & 0.97 & $0.7 \mid-1.33$ & 0.846 \\
\hline
\end{tabular}

Abbreviations: 6MWD, 6-minute walking distance; $95 \% \mathrm{Cl}, 95 \%$ confidence interval; ADO, age/dyspnea/airflow obstruction; BMI, body mass index; BODE, body mass index/airflow obstruction/dyspnea/exercise capacity; COPD, chronic obstructive pulmonary disease; DLco/VA, diffusing capacity of the lung for carbon monoxide and alveolar volume ratio; DOSE, dyspnea/airflow obstruction/smoking status/exacerbation frequency; FFMI, fat-free mass index; GOLD, Global initiative for chronic Obstructive Lung Disease; LAA\%, percentage of low-attenuation area; LTOT, long-term oxygen therapy; MMRC, Modified Medical Research Council dyspnea scale; Previous exacerbation, COPD exacerbation within the previous year; $\mathrm{FEV}_{1}$, forced expiratory volume in I second.

\section{Comparisons of the three indices and frequency of previous exacerbations}

The results of a comparison of other clinical indicators with the three multidimensional indices and the frequency of exacerbations in the previous year are shown in Table 4. All

Table 3 Adjusted multivariate logistic regression analysis of predictors of COPD exacerbation

\begin{tabular}{lllll}
\hline Model & Variable & Odds ratio & $\mathbf{9 5 \%} \mathbf{C l}$ & P-value \\
\hline Model I: GOLD & MMRC & $\mathbf{1} .8 \mathrm{I}$ & $\mathrm{I} .26-2.59$ & $0.00 \mathrm{I}$ \\
& Previous AE & 2.98 & $1.92-4.65$ & $<0.00 \mathrm{I}$ \\
\multirow{3}{*}{ Model II: BODE } & LTOT use & 2.92 & $\mathrm{I} .45-5.87$ & 0.003 \\
& Previous AE & 2.57 & $\mathrm{I} .67-3.96$ & $<0.00 \mathrm{I}$ \\
Model III: ADO & ADO index & $\mathrm{I} .40$ & $\mathrm{I} .13-1.73$ & 0.002 \\
& Previous AE & 2.92 & $\mathrm{I} .89-4.52$ & $<0.00 \mathrm{I}$ \\
\multirow{2}{*}{ Model IV: DOSE } & DOSE index & 2.19 & $\mathrm{I} .52-3.14$ & $<0.00 \mathrm{I}$ \\
& LTOT use & 2.37 & $\mathrm{I} .12-5.0 \mathrm{I}$ & 0.024 \\
\hline
\end{tabular}

Notes: Model I: included all of the variables selected in the univariate analyses except for the BODE, ADO, and DOSE indices. Model II: included the BODE index and replaced GOLD stage, MMRC, and 6MWD. Model III: included the ADO index and 6MWD and replaced the BODE index. Model IV: included the DOSE index and replaced the ADO index and exacerbation of COPD within the previous year. Abbreviations: $95 \% \mathrm{Cl}, 95 \%$ confidence interval; ADO, age/dyspnea/airflow obstruction; BODE, body mass index/airflow obstruction/dyspnea/exercise capacity; COPD, chronic obstructive pulmonary disease; DOSE, dyspnea/airflow obstruction/ smoking status/exacerbation frequency; GOLD, Global initiative for chronic Obstructive Lung Disease; LTOT, long-term oxygen therapy; MMRC, Modified Medical Research Council dyspnea scale; Previous AE, COPD exacerbation within the previous year. of the multidimensional indices were significantly correlated with hypercapnia, exercise capacity, LAA\%, and FFMI, whereas the previous exacerbation rate correlated weakly only with BMI and LAA $\%$.

\section{Discussion}

In the present study, we first tested whether any of three multidimensional assessment systems, ie, the BODE, ADO, and DOSE indices, where suitable for predicting COPD exacerbations. We considered the DOSE index better than the two other multidimensional assessments based on the following three findings. Firstly, the AUC-ROC of the DOSE index was the largest of the three indices (Figure 2). Secondly, the DOSE index remained a factor after multiple comparisons (Table 3). Thirdly, although it is reported that the frequency of exacerbations in the previous year can predict the frequency in the next year, ${ }^{2,15}$ the present study also found that the DOSE index correlated with many clinical parameters besides the frequency of exacerbations in the previous year (Table 4). While it is true that the DOSE index alone includes frequency of exacerbations, we believe this is a strength of the index compared to the BODE or the ADO indices. Using the DOSE index requires clinicians to record these exacerbation rates, which helps provide the correct information to guide management. However, the DOSE index also predicted hypercapnea and exercise capacity (Table 4). More recently, Sundh et $a{ }^{16}$ reported that the DOSE index was a good predictor of mortality in COPD patients in primary and secondary care settings. These results suggest that the DOSE index is a practical tool for assessing current symptoms and future risk in COPD,${ }^{17}$ and we can now confirm that the DOSE index is a stronger predictor than the BODE and $\mathrm{ADO}$ indices for predicting the probability of future exacerbations.

The prediction of outcomes in COPD with multidimensional assessments has been described in two previous reports. The first, by Faganello et al, ${ }^{18}$ concluded that the BODE index was almost equivalent to the GOLD classification for prediction of outcomes. The mean age of the patients in their study was 64.8 years, while the mean age of patients in the present study was 71.0 years, and the disease severity in their cohort (GOLD stages III or IV, 43.7\%) was similar to ours (GOLD stages III or IV, 43\%). The AUC for the BODE index as a predictor of exacerbations was 0.62 in the previous study and 0.65 in the present study. Although the cohorts were similar, the prior study did not evaluate the frequency of exacerbations in the previous year, which might have resulted in different conclusions. The second study, by Marin et al, ${ }^{19}$ found the BODE index useful for predicting exacerbations. The AUC 
Table 4 Correlations between the multidimensional assessment systems or previous exacerbation rate and markers of disease severity

\begin{tabular}{|c|c|c|c|c|c|c|c|c|}
\hline \multirow[t]{2}{*}{ Variable } & \multicolumn{2}{|c|}{ BODE index } & \multicolumn{2}{|c|}{ ADO index } & \multicolumn{2}{|c|}{ DOSE index } & \multicolumn{2}{|c|}{$\begin{array}{l}\text { Previous } \\
\text { exacerbation rate }\end{array}$} \\
\hline & $\rho$ & $P$-value & $\rho$ & $P$-value & $\rho$ & $P$-value & $\rho$ & $P$-value \\
\hline $\mathrm{BMI}$ & -0.491 & $<0.001$ & -0.275 & $<0.001$ & -0.328 & $<0.001$ & -0.165 & 0.026 \\
\hline FFMI & -0.514 & $<0.001$ & -0.420 & $<0.001$ & -0.371 & $<0.001$ & -0.125 & 0.110 \\
\hline 6MWD & -0.669 & $<0.001$ & -0.752 & $<0.001$ & -0.608 & $<0.001$ & -0.024 & 0.749 \\
\hline $\mathrm{PaO}_{2}$ & -0.194 & 0.012 & -0.209 & 0.007 & -0.188 & 0.015 & 0.014 & 0.855 \\
\hline $\mathrm{PaCO}_{2}$ & 0.353 & $<0.001$ & 0.258 & 0.001 & 0.313 & $<0.001$ & 0.036 & 0.644 \\
\hline$\%$ DLco/VA & -0.403 & $<0.001$ & -0.267 & $<0.001$ & -0.335 & $<0.001$ & -0.104 & 0.162 \\
\hline LAA\% & 0.570 & $<0.001$ & 0.372 & $<0.001$ & 0.485 & $<0.001$ & 0.161 & 0.030 \\
\hline WA\% & -0.320 & 0.689 & -0.320 & 0.693 & 0.000 & 0.998 & 0.052 & 0.693 \\
\hline
\end{tabular}

Abbreviations: $\rho$, Spearman's rank correlation coefficient; 6MWD, 6-min walking distance; ADO, age/dyspnea/airflow obstruction; BMI, body mass index; BODE, body mass index/airflow obstruction/dyspnea/exercise capacity; DLco/VA, diffusing capacity of the lung for carbon monoxide and alveolar volume ratio; DOSE, dyspnea/airflow obstruction/smoking status/exacerbation frequency; FFMI, fat-free mass index; GOLD, Global initiative for chronic Obstructive Lung Disease; LAA\%, percentage of lowattenuation area; WA\%, percentage of wall area.

was 0.81 in their study. Closer examination of the distribution of the BODE scores in the present study revealed that $7.1 \%$ of the patients fell into quartile 4 (BODE score 7 to 10 ) (Figure S2). We postulated that this was due to the relatively small anthropometric measurements of the Japanese population compared with those of western populations. Current data indicate that BMI differs significantly between Caucasian and Asian individuals. ${ }^{20}$ Thus, it might not be appropriate to apply the original BODE index 5 to Asian populations because it could affect the cutoff values for the criteria. A further study is required on the adjustment of this index for different ethnicities.

In this study, we defined exacerbations according to the previous recommendation by using patient self-reporting of symptoms and diaries. ${ }^{21,22}$ However, it should be noted that the definition of exacerbations is known to significantly affect the frequency, and symptom-based counts are generally greater than event-based counts. ${ }^{23}$ In the present study, approximately $10 \%$ of the patients did not receive antibiotics or systemic steroids or did not visit the emergency department for treatment of exacerbations (Table S1). This raises the question of whether these cases should have been excluded because these events would not be counted as event-based exacerbations. However, the DOSE index appeared superior even when such cases were excluded from the results (Table S2).

Daily diaries may be used to collect data on disease activity, but are burdensome and compliance may be poor. Walters et $\mathrm{al}^{24}$ investigated diary-keeping in COPD and ascertained the items that best predicted emergency attendances for exacerbations. They conclude that good compliance can be achieved using daily diaries in COPD, although this is worse in those with poor educational level, whereas
Bischoff et $\mathrm{al}^{25}$ report that an automated telephonic exacerbation assessment system is a valid tool to assess COPD exacerbation rate in prospective clinical study. In this study, we not only used diaries but also systematically asked patients every month to minimize recall bias.

The frequency of exacerbations in this study was 0.48 to 0.57 events per patient-year. These frequencies were lower than those reported in large-cohort studies such as the TORCH and UPLIFT studies, which reported frequencies of 0.85 to 1.13 and 0.73 to 0.85 events per patient-year, respectively. ${ }^{26,27}$ It is helpful to compare our results with other data regarding the frequency of exacerbations in a cohort of Japanese patients with COPD, and the data from 3 previous reports appear to be consistent with data from the present study. Firstly, the frequency of exacerbations in the Hokkaido Cohort study ${ }^{28}$ was 0.22 events per patient-year in 279 exclusively Japanese participants over 5 years, a lower rate than that observed in the present study. Second, a subanalysis of the UPLIFT study, ${ }^{29}$ that compared the frequency of exacerbations between Japanese and other Asian patients and Caucasian patients found that the frequencies were lower in the former group, suggesting that Japanese COPD patients are, in general, likely to experience exacerbations at a lower frequency. Finally, the frequency reported in the original DOSE manuscript, ${ }^{7}$ which used data from Tokyo, showed a close conformance to the frequency in the present study. This may be explained by the fact that all Japanese residents are covered by a medical insurance system that is supported by the government, with about $10 \%-30 \%$ of total expenditures borne by each patient of any age. ${ }^{30}$ Universal access to medical treatment in Japan may encourage early treatment, possibly resulting in a reduced frequency 
of acute COPD exacerbations. Moreover, we speculated that different ethnic and socioeconomic status would have different outcomes in terms of acute exacerbations. We previously reported that exacerbations were more frequent in participants with COPD who lived alone than in participants who lived in in-home caregiver groups. ${ }^{31}$ Furthermore, previous data have indicated that a low income and/or educational level were independently related to the risk of COPD exacerbation. ${ }^{32}$ In addition, the percentage of current smokers, $4.4 \%$, was much smaller in our study than in the TORCH and UPLIFT studies (43\% and 29\%, respectively). The lower frequency of exacerbation in the present study, as well as other studies from Japan, ${ }^{28,29}$ may also give rise to speculation that individuals of different ethnicities show different phenotypes of COPD. ${ }^{33}$ Clearly, these hypotheses require further study.

There are strengths in the present study. We recorded the occurrence of exacerbations monthly, and the patients were asked directly to describe detailed changes in symptoms or clinical features from the last visit. In a previous study, Langsetmo et $\mathrm{al}^{34}$ reported that detecting mild exacerbations could be problematic. In their study, patients were asked to contact the study center if sustained worsening of a symptom occurred; therefore, reported exacerbations were events that led the patient to contact the study center or appear for a health care visit. However, in our study, the patients were asked to visit every month regardless of any exacerbations. This method is complicated and can be burdensome for patients, but we believe that it is a reliable method and is therefore an advantage of this study.

The present study also had several limitations. The study was performed at a university clinic, and all patients were managed under the supervision of chest specialist physicians and well-trained nurses. However, most of our patients were in GOLD stage II, which might not be the best group to evaluate for exacerbation risk. In addition, the relatively small sample size may make it difficult to extend the findings to the general patient population. Furthermore, we did not examine the effects of chronic expectoration, comorbidities such as gastroesophageal reflux syndrome, or different pharmaceutical regimens, all of which are known risk factors for exacerbation of COPD. ${ }^{35,36}$ These considerations should be addressed in further studies.

\section{Conclusion}

We compared three multidimensional assessments for prediction of exacerbation of COPD. The DOSE index was better at predicting exacerbations of COPD than the BODE and ADO indices. Furthermore, because the DOSE index incorporates annual exacerbation rates, the use of the DOSE index encourages clinicians to collect annual exacerbation rates, which are crucial for providers and patients who must make COPD management decisions for determining optimal treatment.

\section{Disclosure}

The authors report no conflicts of interest in this work.

\section{References}

1. Global Initiative for Chronic Obstructive Lung Disease. Global Strategy for the Diagnosis, Management, and Prevention of Chronic Obstructive Pulmonary Disease; updated 2013. Available from: http://www. goldcopd.org/uploads/users/files/GOLD_Report_2013_Feb20.pdf. Accessed January 2013

2. Seemungal TA, Donaldson GC, Paul EA, Bestall JC, Jeffries DJ, Wedzicha JA. Effect of exacerbation on quality of life in patients with chronic obstructive pulmonary disease. Am J Respir Crit Care Med. 1998;157:1418-1422.

3. Miravitlles M, Guerrero T, Mayordomo C, Sanchez-Agudo L, Nicolau F, Segu JL. Factors associated with increased risk of exacerbation and hospital admission in a cohort of ambulatory COPD patients: a multiple logistic regression analysis. The EOLO Study Group. Respiration. 2000;67:495-501.

4. Niewoehner DE, Lokhnygina Y, Rice K, et al. Risk indexes for exacerbations and hospitalizations due to COPD. Chest. 2007;131:20-28.

5. Celli BR, Cote CG, Marin JM, et al. The body-mass index, airflow obstruction, dyspnea, and exercise capacity index in chronic obstructive pulmonary disease. $N$ Engl J Med. 2004;350:1005-1012.

6. Puhan MA, Garcia-Aymerich J, Frey M, et al. Expansion of the prognostic assessment of patients with chronic obstructive pulmonary disease: the updated BODE index and the ADO index. Lancet. 2009; 374:704-711.

7. Jones RC, Donaldson GC, Chavannes NH, et al. Derivation and validation of a composite index of severity in chronic obstructive pulmonary disease: the DOSE Index. Am J Respir Crit Care Med. 2009;180: 1189-1195.

8. Rabe KF, Hurd S, Anzueto A, et al. Global strategy for the diagnosis, management, and prevention of chronic obstructive pulmonary disease: GOLD executive summary. Am J Respir Crit Care Med. 2007;176: $532-555$.

9. No authors listed. Standardization of Spirometry, 1994 Update. American Thoracic Society. Am J Respir Crit Care Med. 1995;152:1107-1136.

10. Japanese Respiratory Society. The predicted values of spirometry and arterial blood gas analysis in Japanese. J Jap Resp Soc. 2001;39. Appendix (In Japanese)

11. Mahler DA, Wells CK. Evaluation of clinical methods for rating dyspnea. Chest. 1988;93:580-586.

12. ATS Committee on Proficiency Standards for Clinical Pulmonary Function Laboratories. ATS statement: guidelines for the six-minute walk test. Am J Respir Crit Care Med. 2002;166:111-117.

13. Charlson ME, Pompei P, Ales KL, MacKenzie CR. A new method of classifying prognostic comorbidity in longitudinal studies: development and validation. J Chronic Dis. 1987;40:373-383.

14. Hosmer DW, Lemeshow S. Applied Logistic Regression, 2nd ed. Hoboken, NJ, USA: John Wiley \& Sons; 2000.

15. Hurst JR, Vestbo J, Anzueto A, et al. Susceptibility to exacerbation in chronic obstructive pulmonary disease. $N$ Engl J Med. 2010;363: $1128-1138$.

16. Sundh J, Janson C, Lisspers K, Stallberg B, Montgomery S. The Dyspnoea, Obstruction, Smoking, Exacerbation (DOSE) index is predictive of mortality in COPD. Prim Care Respir J. 2012;21: 295-301. 
17. Chavannes NH, Jones RC, Postma DS, Rennard S. Using COPD multidimensional indices in routine clinical practice: DOSE meets all criteria. Prim Care Respir J. 2012;21:245-246.

18. Faganello MM, Tanni SE, Sanchez FF, Pelegrino NR, Lucheta PA, Godoy I. BODE index and GOLD staging as predictors of 1-year exacerbation risk in chronic obstructive pulmonary disease. Am J Med Sci. 2010;339:10-14.

19. Marin JM, Carrizo SJ, Casanova C, et al. Prediction of risk of COPD exacerbations by the BODE index. Respir Med. 2009;103:373-378.

20. WHO Expert Consultation. Appropriate body-mass index for Asian populations and its implications for policy and intervention strategies. Lancet. 2004;363:157-163.

21. Donaldson GC, Seemungal TA, Patel IS, Lloyd-Owen SJ, Wilkinson TM, Wedzicha JA. Longitudinal changes in the nature, severity and frequency of COPD exacerbations. Eur Respir J. 2003;22:931-936.

22. Quint JK, Donaldson GC, Hurst JR, Goldring JJ, Seemungal TR, Wedzicha JA. Predictive accuracy of patient-reported exacerbation frequency in COPD. Eur Respir J. 2011;37:501-507.

23. Effing TW, Kerstjens HA, Monninkhof EM, et al. Definitions of exacerbations: does it really matter in clinical trials on COPD? Chest. 2009;136:918-923.

24. Walters EH, Walters J, Wills KE, Robinson A, Wood-Baker R. Clinical diaries in COPD: compliance and utility in predicting acute exacerbations. Int J Chron Obstruct Pulmon Dis. 2012;7:427-435.

25. Bischoff EW, Boer LM, Molema J, et al. Validity of an automated telephonic system to assess COPD exacerbation rates. Eur Respir J. 2012;39:1090-1096.

26. Calverley PM, Anderson JA, Celli B, et al. Salmeterol and fluticasone propionate and survival in chronic obstructive pulmonary disease. N Engl J Med. 2007;356:775-789.
27. Tashkin DP, Celli B, Senn S, et al. A 4-year trial of tiotropium in chronic obstructive pulmonary disease. $N$ Engl J Med. 2008;359:1543-1554.

28. Nishimura M, Makita H, Nagai K, et al. Annual change in pulmonary function and clinical phenotype in chronic obstructive pulmonary disease. Am J Respir Crit Care Med. 2012;185:44-52.

29. Fukuchi Y, Fernandez L, Kuo HP, et al. Efficacy of tiotropium in COPD patients from Asia: a subgroup analysis from the UPLIFT trial. Respirology. 2011;16:825-835.

30. Ikegami N, Yoo BK, Hashimoto H, et al. Japanese universal health coverage: evolution, achievements, and challenges. Lancet. 2011;378: 1106-1115.

31. Wakabayashi R, Motegi T, Yamada K, Ishii T, Gemma A, Kida K. Presence of in-home caregiver and health outcomes of older adults with chronic obstructive pulmonary disease. J Am Geriatr Soc. 2011;59: 44-49.

32. Eisner MD, Blanc PD, Omachi TA, et al. Socioeconomic status, race and COPD health outcomes. J Epidemiol Community Health. 2011;65:26-34.

33. Han MK, Curran-Everett D, Dransfield MT, et al. Racial differences in quality of life in patients with COPD. Chest. 2011;140:1169-1176.

34. Langsetmo L, Platt RW, Ernst P, Bourbeau J. Underreporting exacerbation of chronic obstructive pulmonary disease in a longitudinal cohort. Am J Respir Crit Care Med. 2008;177:396-401.

35. Burgel PR, Nesme-Meyer P, Chanez P, et al. Cough and sputum production are associated with frequent exacerbations and hospitalizations in COPD subjects. Chest. 2009;135:975-982.

36. Terada K, Muro S, Sato S, et al. Impact of gastro-oesophageal reflux disease symptoms on COPD exacerbation. Thorax. 2008;63: 951-955. 


\section{Supplementary materials Methods}

\section{Participants}

Inclusion criteria for entry

A total of 232 patients with chronic obstructive pulmonary disease (COPD) were initially recruited by the outpatient clinic of the Respiratory Care Clinic (RCC) at Nippon Medical School, Tokyo, Japan, a secondary care specialty COPD clinic, from April 2007 to October 2007 (run-in period).

Patients were eligible for inclusion in the study if they met all of the following criteria:

- A diagnosis of COPD by a chest physician

- Current or former smoking history of at least 20 packyears

- Age of $\geq 40$ years.

\section{Exclusion criteria}

Subjects were not eligible for inclusion in the study if any of the following criteria applied:

- A diagnosis of bronchial asthma, bronchiectasis, or bullous lung disease

- Active tuberculosis or any history of pulmonary fibrosis

- Withdrawal of consent

- A diagnosis of any malignancy

- A diagnosis of dementia.

Thus, 26 patients were excluded during the run-in period, and a final cohort of 206 patients was followed from November 2007 to October 2009.

\section{Assessment of exacerbations}

All assessments were performed for each patient at 1- or 2-month intervals. First, each patient was asked whether he or she had noticed any changes in symptoms, had received extra or alternative treatments, or had suspected an exacerbation. Then, each patient's diary was checked for any changes in reports of breathlessness, cough, increased or changed amount or color of sputum, fever, or wheezing. Attached is a sample diary that was used in this study (Figure S1). Patients were asked to keep a daily record of their symptoms in the diary. The diary card consisted of major symptoms (dyspnea, sputum volume, and sputum color) and minor symptoms (sore throat, fever, cough, common cold, and wheezing). Patients were instructed to note whether they had contacted a health care provider, increased their inhalation medication, or started a course of corticosteroids or antibiotics. An exacerbation was determined to have occurred when these self-assessments and the descriptions in the diary agreed. If the two accounts disagreed, one of the authors (a chest physician specialist) performed a more detailed inquiry regarding the specific symptoms and the clinical course and subsequently determined whether an exacerbation had occurred. Furthermore, if patients had received any treatments at another medical institution due to changes in respiratory symptoms, they were determined to have experienced an exacerbation. If the occurrence of an exacerbation was uncertain based on the diary descriptions, the patient's chest physician decided whether an exacerbation had occurred. Any exacerbations occurring within 4 weeks of each other were considered a single exacerbation.

Once each exacerbation was determined, each patient's responses were studied and recorded. A patient's response was recorded based on one of five options: (1) no use of medication or medical therapy; (2) the patient decided to use medication according to a previously prepared action plan; (3) the patient visited the RCC to receive therapy; (4) the patient visited another medical institution; or (5) the patient was hospitalized. The use of the first option could be due to two different scenarios: (1) the exacerbation may have been mild with no antibiotics or oral steroids required; or (2) the patient may have been insufficiently aware of the exacerbation, resulting in a lack of additional therapy.

\section{Analysis of emphysema and airway thickness by computed tomography}

High-resolution computed tomography (HRCT) was performed with a Light Speed Pro16 CT scanner (General Electric Co, Tokyo, Japan) with the following settings: 1.25-mm collimation, 0.8 -second scan time (rotation time), $120 \mathrm{kV}$, and 100-600 mA. To evaluate emphysema quantitatively, the percentage of the low-attenuation area (LAA\%) in the HRCT images was calculated. The LAA $\%$ was calculated by the scanner on 6 slices. The arithmetical mean value of each case was used as the representative value of LAA\%. The cut-off level between normal lung-density area and LAA was defined as $-960 \mathrm{HU} .{ }^{1}$ In addition, the dimensions of the right apical segmental bronchus were measured and the percentage of the airway wall area (WA\%) was calculated ${ }^{1}$ to evaluate airway narrowing.

\section{Results}

\section{Data on patients with exacerbations}

The total number of events in the first year was 105, and the event rate was 0.57 events per patient-year. The numbers 


\begin{tabular}{|c|c|c|c|c|c|}
\hline Date & & & & & $k^{* *}$ \\
\hline Body tem & & & & & \\
\hline Pulse rate & & & & & \\
\hline Body wei & & & & & \\
\hline Feeling & Good & & 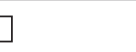 & & $\square$ \\
\hline & Bad & & ] & & $\square$ \\
\hline Cough & None & & ] & & $\square$ \\
\hline & Mild & & ] & & $\square$ \\
\hline & Strong & & 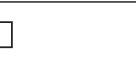 & & $\square$ \\
\hline Sputum & None & & ] & & $\square$ \\
\hline & $\begin{array}{l}\text { Less } \\
\text { (white/yellow/green) }\end{array}$ & $\square \mathrm{n}$ & $\mathrm{YY} \square \mathrm{G}$ & $\square \mathrm{W}$ & $\mathrm{Y} \square \mathrm{G}$ \\
\hline & $\begin{array}{l}\text { Large } \\
\text { (white/yellow/green) }\end{array}$ & $\square \mathrm{n}$ & $\mathrm{Y} \square \mathrm{G}$ & $\square \mathrm{W}$ & $\mathrm{Y} \square \mathrm{G}$ \\
\hline Dyspnea & Resting/Exercise & Resting & Exercise & Resting & Exercise \\
\hline & None & $\square$ & $\square$ & $\square$ & $\square$ \\
\hline & Mild & $\square$ & $\square$ & $\square$ & $\square$ \\
\hline & Strong & $\square$ & $\square$ & $\square$ & $\square$ \\
\hline Leg edem & & $\square \mathrm{n}$ & $\square$ Yes & $\square \mathrm{Nc}$ & $\square$ Yes \\
\hline $\begin{array}{l}\text { Other syn } \\
\text { fever, cou } \\
\text { wheezing }\end{array}$ & $\begin{array}{l}\text { sore throat, } \\
\text { nmon cold, }\end{array}$ & $\begin{array}{l}\square \mathrm{N} \\
\text { sy }\end{array}$ & $\begin{array}{l}\square \text { Yes } \\
\text { oms }\end{array}$ & $\begin{array}{l}\square \mathrm{p} \\
\text { Sy }\end{array}$ & $\begin{array}{l}\square \text { Yes } \\
\text { toms }\end{array}$ \\
\hline & & ( & ) & ( & 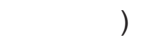 \\
\hline Additiona & & $\begin{array}{r}\square \text { Colc } \\
\square \text { A } \\
\square\end{array}$ & $\begin{array}{l}\text { dicine } \\
\text { otics } \\
\text { oids }\end{array}$ & $\begin{array}{r}\square \text { Col } \\
\square \mathrm{A} \\
\square\end{array}$ & $\begin{array}{l}\text { edicine } \\
\text { biotics } \\
\text { aroids }\end{array}$ \\
\hline Unschedu & & $\square \wedge$ & $\nabla$ Yes & $\square$ & $\square$ Yes \\
\hline Number c & & & & & steps \\
\hline Exercise & & $\square \mathrm{Y}$ & $\square$ No & $\square$ & $\square$ No \\
\hline Appetite & & $\square \mathrm{Y}$ & $\square$ No & $\square$ & $\square$ No \\
\hline Oxygen $u$ & me, hours & & & & ${ }^{*} \mathrm{~h}$ \\
\hline Others & & & & & \\
\hline
\end{tabular}

Figure SI Sample diary used in the present study.

of patients experiencing one, two, and three or more events during the first year were 34,18 , and ten, respectively. In the second year, the total number of events was 88 (in a total of 64 patients), and the exacerbation rate was 0.48 events per patient-year. The numbers of patients experiencing one, two, and three or more events were 47,12, and five, respectively.

Patients experiencing a total of 79 of the 88 events in the second year received some type of medical intervention in response to the exacerbation. These interventions included the use of certain medications in accordance with previously established action plans that had been formulated individually for each patient (19 events; $21.6 \%$ ), unscheduled visits to the RCC (24 events; $27.3 \%$ ), visits to other medical institutions (20 events; $22.7 \%$ ), and hospitalizations (16 events; $18.2 \%)$. The remaining nine events (10.2\%) did not involve any treatment for exacerbations (Table S1). Of these nine events, two, three, and four occurred in Global 
Table SI Patient responses to 88 exacerbations reported in the second year of the study period

\begin{tabular}{ll}
\hline Patient's response & Number (\%) \\
\hline No visit or no additional medication & $9(10.2)$ \\
Medication taken based on patient's self-assessment & $19(21.6)$ \\
Action plan used & 18 \\
Over-the-counter treatment & 1 \\
Visit to the RCC & $24(27.3)$ \\
Direct visit to the RCC & 16 \\
Visit to the RCC after taking medication & 7 \\
on self-judgment & \\
Visit to the RCC after visiting another clinic & 1 \\
Visit to another clinic or hospital & $20(22.7)$ \\
Direct visit to another clinic or hospital & 18 \\
Visit to another clinic or hospital after & 2 \\
taking medicine on self-assessment & \\
Hospitalization & $16(18.2)$ \\
After visiting another clinic or hospital & 5 \\
After visiting the RCC & 2 \\
Not known how patient was admitted & 9 \\
\hline
\end{tabular}

Abbreviation: RCC, respiratory care clinic.

initiative for chronic Obstructive Lung Disease (GOLD) stage I, II, and III patients, respectively, and six and three patients experienced one exacerbation and $\geq 2$ exacerbations, respectively. None of these patients experienced further exacerbations within 4 weeks after the first exacerbation, suggesting that these were very mild exacerbations treatable by add-on therapy with short-acting beta-adrenergic regimens. Of the three patients who experienced more than two exacerbations within the year, two had been enrolled with previously formulated action plans. The remaining patient could not decide on a therapy at the time of the first exacerbation, but was able to do so by the time of the second exacerbation. Therefore, all 88 events in this study were classified as exacerbations according to a symptom-based definition. However, nine of these events were not treated with antibiotics or systemic steroids, and were therefore excluded. The results of the re-analysis from which the six patients who experienced only one untreated exacerbation were excluded are shown in Table S2; even in the absence of these ambiguous symptom-defined events, the DOSE index remained superior in this analysis.

\section{Outcome study of the enrolled patients and those who dropped out}

Of the 206 total patients followed over the 2-year period (November 2007 to October 2009), 23 dropped out of the study. During the first year of the study, 20 patients dropped out, including 15 who could not be followed up because they
Table S2 C-statistics for the multidimensional grading systems, GOLD stage, and previous exacerbation rate as predictors of an exacerbation during the I-year follow-up (excluding six patients who did not receive medical intervention)

\begin{tabular}{lll}
\hline & $\begin{array}{l}\text { AUC (95\% confidence } \\
\text { interval) }\end{array}$ & P-value \\
\hline GOLD stage & $0.66(0.57-0.74)$ & $0.00 \mathrm{I}$ \\
BODE index & $0.64(0.55-0.72)$ & 0.004 \\
ADO index & $0.64(0.55-0.73)$ & 0.003 \\
DOSE index & $0.75(0.67-0.82)$ & $<0.00 \mathrm{I}$ \\
Previous exacerbation rate $^{\mathrm{a}}$ & $0.73(0.64-0.82)$ & $<0.00 \mathrm{I}$ \\
\hline
\end{tabular}

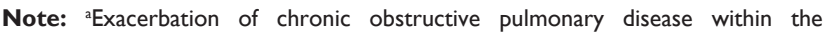
previous year.

Abbreviations: ADO, age/dyspnea/airflow obstruction; AUC, area under the curve; BODE, body mass index/airflow obstruction/dyspnea/exercise capacity; DOSE, dyspnea/airflow obstruction/smoking status/exacerbation frequency; GOLD, Global initiative for chronic Obstructive Lung Disease.

transferred to other medical institutes, one who stopped visiting regularly, and four who died within the year. The causes of death of the patients who died during the first year were as follows: one died suddenly at his home (GOLD stage IV and using NPPV), two died of worsening respiratory failure during hospitalization for exacerbations (both were GOLD stage III), and the last died of heart failure (GOLD stage II).

During the second year, three patients dropped out (all stopped visiting the RCC). All 23 patients who dropped out were excluded from the final analysis. However, two patients died during the second year after all of the data from the first year were completely collected, and these two cases were included. The causes of death of the patients who died during the second year were exacerbation of COPD in one case and lung cancer in the other case.

During the 2-year period, 17 patients transferred to other medical institutions, including two who developed lung cancer (one each in GOLD stages III and IV). The other 15 patients stopped visiting because the distances between their homes and the RCC were too great to allow regular visits (these patients were in GOLD stages I [ $\mathrm{n}=3]$, II [ $\mathrm{n}=7]$, III [ $\mathrm{n}=3]$, and IV [ $\mathrm{n}=2])$.

\section{Classification of patients by GOLD stages and BODE, ADO, and DOSE indices}

The distributions of patient numbers and GOLD stages according to body mass index/airflow obstruction/dyspnea/ exercise capacity (BODE), age/dyspnea/airflow obstruction (ADO), and dyspnea/airflow obstruction/smoking status/ exacerbation frequency (DOSE) index scores are shown in Figure S2. 

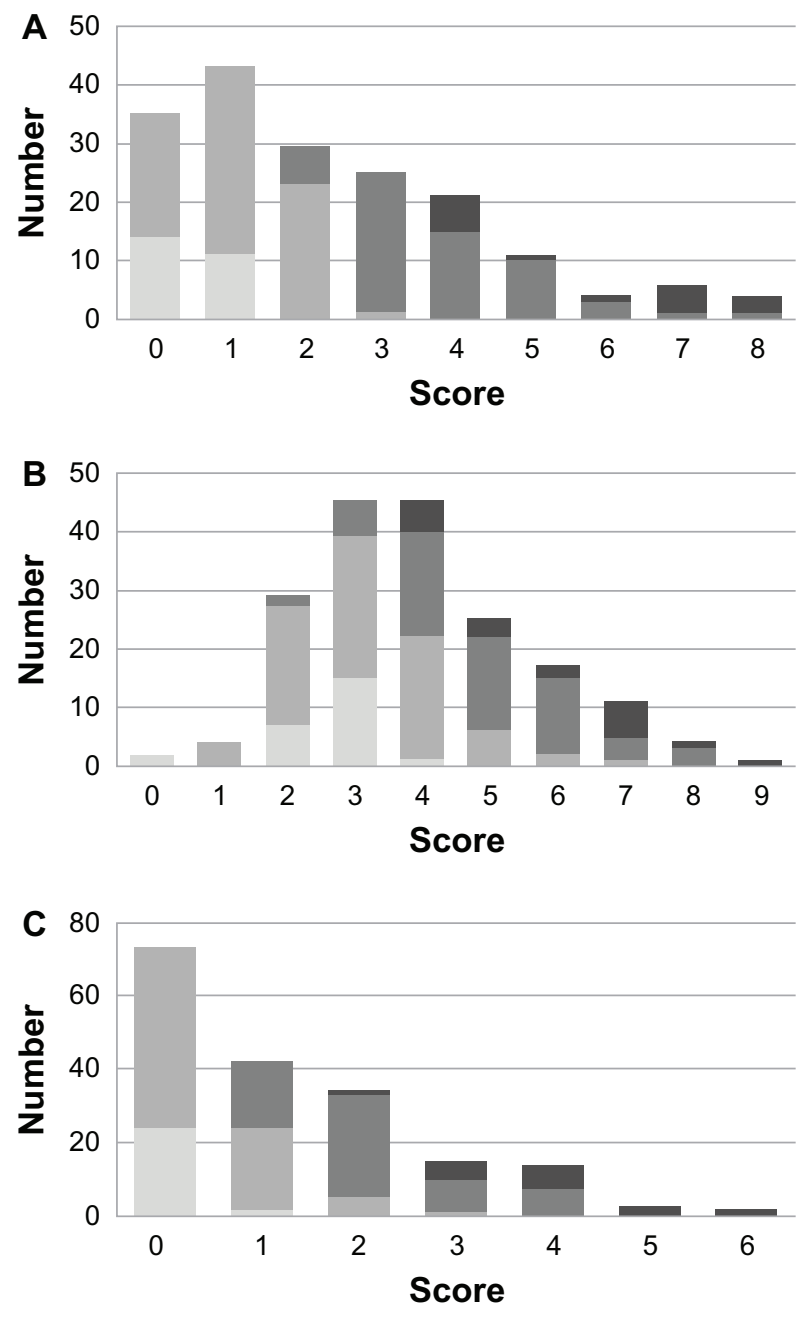

\section{$\begin{array}{llll}\text { Stage } 1 & \text { Stage } 2 \square \text { Stage } 3 \quad \text { Stage } 4\end{array}$}

Figure S2 Distributions of GOLD stages and total numbers of patients according to the scores of each multidimensional grading system. (A) BODE index; (B) ADO index; (C) DOSE index.

Abbreviations: ADO, age/dyspnea/airflow obstruction; BODE, body mass index/ airflow obstruction/dyspnea/exercise capacity; DOSE, dyspnea/airflow obstruction/ smoking status/exacerbation frequency; GOLD, Global initiative for chronic Obstructive Lung Disease.

\section{References}

1. Ohara $\mathrm{T}$, Hirai $\mathrm{T}$, Sato $\mathrm{S}$, et al. Longitudinal study of airway dimensions in chronic obstructive pulmonary disease using computed tomography. Respirology. 2008;13:372-378.

International Journal of COPD

\section{Publish your work in this journal}

The International Journal of COPD is an international, peer-reviewed journal of therapeutics and pharmacology focusing on concise rapid reporting of clinical studies and reviews in COPD. Special focus is given to the pathophysiological processes underlying the disease, intervention programs, patient focused education, and self management protocols. 